\title{
Chicken or the egg: the dilemma of allergic rhinitis versus adenoid hypertrophy*
}

\author{
Erdem Eren', Seçil Arslanoğlu', Semiha Bahçeci Erdem², Tekin Nacaroğlu², \\ Canan Şule Karkıner², Demet Can², Kazım Önal ${ }^{1}$ \\ 1 Izmir Katip Çelebi University Atatürk Research and Education Hospital, Department of Otolaryngology Head \& Neck Surgery, \\ Izmir, Turkey \\ 2 Izmir Behçet Uz Children Hospital Department of Pediatric Allergy, Izmir, Turkey
}

Rhinology 53: 154-159, 2015

DOl:10.4193/Rhino14.013

*Received for publication:

January 27, 2014

Accepted: September 28, 2014

\begin{abstract}
Background: There is no consensus as to whether allergic rhinitis (AR) is a cause of adenoid hypertrophy (AH). This study evaluated the role of allergy in $\mathrm{AH}$, and it explored the role of nasal endoscopy and the history of diagnosing AR in children empirically.

Materials and Methods: This study enrolled 155 children consecutively in İzmir Behçet Uz Children's Hospital between January and September 2013.

Results: Of the patients, 101 (65.2\%) had a positive skin prick test. Multiple allergen sensitivity was identified in 76 (75.2\%) of these patients. The history items of itching and sneezing had predictive value for empirically diagnosing AR in children. Of the nasal examination findings, only the nasal secretion characteristics had significant predictive value. AH and AR had a significant negative correlation.
\end{abstract}

Conclusion: In this study, AH and AR were inversely related. The characteristics of the nasal secretions, itching, sneezing, were predictors of AR in children.

Keywords: adenoid, allergy, children

\section{Introduction}

Adenoid hypertrophy $(\mathrm{AH})$ is one of the most frequent indications for surgery in the paediatric population ${ }^{(1)}$. Nasal obstruction, open-mouth breathing, and snoring are symptoms of AH. As these symptoms are non-specific, a careful physical examination is mandatory. Allergic rhinitis (AR) is one of the most common chronic diseases in children ${ }^{(2)}$. Enlargement of the inferior turbinates will cause nasal obstruction. In children, AR and AH have similar symptoms that need to be differentiated at the time of consultation.

Several studies have investigated the relationship between $\mathrm{AH}$ and AR. Some reports suggest that AR plays a role in $\mathrm{AH}^{(3)}$, while others found no such relationship ${ }^{(4)}$. The main drawback of these studies is that lateral neck X-rays are used to diagnose $\mathrm{AH}$. Nasal endoscopy is an accurate method for assessing $\mathrm{AH}^{(5)}$ providing better visualization of the nasopharynx and a more accurate evaluation of adenoid size ${ }^{(6,7)}$.

Physicians in primary and secondary healthcare settings tend to rely only on history and a nasal examination to diagnose allergies. However, the nasal examination is subject to inter- and intra-observer variability, and the patient history alone is not of diagnostic value for AR. Ameli et al. ${ }^{(8)}$ investigated nasal endoscopy signs that predicted allergy in 176 children and reported that inferior and middle turbinate contacts were reliable predictors of AR (odds ratio (OR) 5.38 and 3.42, respectively), whereas pale turbinates did not predict AR. Eren et al. ${ }^{(9)}$ investigated the values of the history and nasal endoscopy signs in adults and stated that neither predicted AR. In addition, the nasal endoscopy signs were subject to great inter-rater variability. Therefore, this study evaluated the role of allergy in $\mathrm{AH}$ and explored the roles of nasal endoscopy and history in diagnosing AR in children empirically. 


\section{Materials and methods}

This study was conducted between January and September 2013 in the İzmir Behçet Uz Children Research and Education Hospital Otolaryngology Clinic. The study included 155 consecutive patients (109 males, 46 females; mean age $8.7 \pm 2.4$ (range 4-12) years) who were referred from the Department of Pediatric Allergy. Written informed consent was obtained from the caregiver of every patient. The İzmir Behçet Uz Children's Research and Education Hospital Ethics Committee approved the study. All of the subjects were recruited on a voluntary basis.

\section{History}

A history of sneezing, rhinoerrhea, nasal obstruction, itching, postnasal drip, coughing, and snoring was recorded. A 4-point scale (four faces representing varying degrees of emotion) was used to evaluate the history: 1 , no complaints; 2 , mild complaints; 3, moderate complaints; and 4, severe complaints ${ }^{(1,10)}$. Number 1 was represented by a happy smiling face, number 4 by a sad face and numbers 2 and 3 were faces with varying degrees of sadness ${ }^{(10)}$.

\section{Physical and nasal endoscopic examination}

A physician blinded to the patients' histories performed the physical examination and nasal endoscopy. Tonsil size was graded according to Brodsky et al. ${ }^{(11)}$. In this scale, 0 indicates that the tonsils do not block the airways, +1 indicates $<25 \%$ airway obstruction, +2 indicates $26-50 \%$ airway obstruction, +3 indicates $51-75 \%$ airway obstruction, and +4 indicates $76-100 \%$ airway obstruction (2). Any cobblestone appearance of the posterior oropharyngeal wall was noted. Adenoid size was graded using the help of a paediatric rigid nasal endoscope after applying topical anaesthesia. The presence of inferior turbinate hypertrophy was defined as contact between the inferior turbinate and lateral wall ${ }^{(8)}$. The presence or absence of nasal secretions (serous-mucoid or absent) and turbinate color (pale or normal) was noted. AH was graded according to Parikh's classification ${ }^{(12)}$. Grade 1 adenoids are non-obstructive, grade 2 adenoids contact the torus tubarious, grade 3 adenoids contact the vomer, and grade 4 adenoids contact the soft palate (at rest) ${ }^{(2)}$. Patients with adenotonsillar surgery, acute rhinosinusitis, and nasal septal deviation, or those using nasal steroids, antihistamines, or antileukotrienes 1 month prior to the evaluation were excluded from the study.

\section{Skin prick test}

All patients were tested for common aeroallergens using standardized ALK-Abelló extracts (ALK, Denmark) containing the extracts from the following allergens: grasses (cocksfoot, meadow fescue, ryegrass, meadow grass, timothy, wheat, and corn), weeds (mugwort, wall pellitory, plantain, and goosefoot), trees (olive, birch, oak, alder, poplar, and plane), mites (Dermatophagoides pteronyssinus and D. farinae), mold (Alternaria), animal danders (cat and dog), and cockroaches. Positive (histamine phosphate $10 \mathrm{mg} / \mathrm{mL}$ ) and negative (saline) control solutions were applied. The tests were read after 15 minutes. The largest and smallest diameters of the wheal and erythema were measured and summed using a transparent millimeter ruler. The results were recorded in millimeters as the mean values of the wheal and flare reactions. Erythema of at least $10 \mathrm{~mm}$ and a wheal that was $3 \mathrm{~mm}$ greater than the negative control were considered a positive response.

\section{Statistical analysis}

The statistical analysis was performed using SPSS ver. 16 . The level of statistical significance was set at $p<0.05$ and the confidence intervals $(\mathrm{Cl})$ at $95 \%$. Anova with post hoc Tukey test was used for multiple comparisons. The chi-square test was used for categorical values and the Pearson's test for correlation analysis. Logistic regression analysis was used to determine the values of each history item and nasal endoscopy examination item to predict allergy.

\section{Results}

The skin prick tests were negative in 54 (34.8\%) and positive in

Table 1. Distribution of allergens and the sex distribution for the specific sensitizations.

\begin{tabular}{|c|c|c|c|c|c|c|c|c|c|c|c|}
\hline & & $\begin{array}{c}\text { D. } \\
\text { pteronyssinus }\end{array}$ & $\begin{array}{c}\text { D. } \\
\text { farinae }\end{array}$ & Alternaria & Cat & Dog & Grasses & Trees & Weeds & Olive & Cockroach \\
\hline \multicolumn{2}{|c|}{ Negative(n,\%) } & $125(81,3)$ & $126(80,6)$ & $128(82,6)$ & $132(85,2)$ & $142(91,6)$ & $139(89,7)$ & $145(93,5)$ & $148(95,5)$ & $110(71)$ & $148(95,5)$ \\
\hline \multicolumn{2}{|c|}{ Positive (n,\%) } & $30(18,7)$ & $29(19,4)$ & $27(17,4)$ & $23(14,8)$ & $13(8,4)$ & $16(10,3)$ & $10(6,5)$ & $7(4,5)$ & $45(29)$ & $7(4,5)$ \\
\hline \multirow{2}{*}{$\begin{array}{l}\text { Negative } \\
(n, \%)\end{array}$} & Female & $37(23,9)$ & $36(23,2)$ & $41(26,5)$ & $41(26,5)$ & $45(29)$ & $41(26,5)$ & $44(28,4)$ & $45(29)$ & $37(23,9)$ & $46(29,7)$ \\
\hline & Male & $89(57,4)$ & $89(57,4)$ & $87(56,1)$ & $91(58,7)$ & $97(62,6)$ & $98(63,2)$ & $101(65,2)$ & $103(66,5)$ & $73(47,1)$ & $102(65,8)$ \\
\hline \multirow{2}{*}{$\begin{array}{l}\text { Positive } \\
(n, \%)\end{array}$} & Female & $9(5,8)$ & $10(6,5)$ & $5(3,2)$ & $5(3,2)$ & $1(0,6)$ & $5(3,2)$ & $2(1,3)$ & $1(0,6)$ & $9(5,8)$ & $0(0)$ \\
\hline & Male & $20(12,9)$ & $20(12,9)$ & $22(14,2)$ & $18(11,6)$ & $12(7,7)$ & $11(7,1)$ & $8(5,2$ & $6(3,9)$ & $36(23,2)$ & $7(4,5)$ \\
\hline
\end{tabular}


101 (65.2\%) patients, of which 76 (75.2\%) had multiple allergen sensitivity (AS) and 25 (24.7\%) reacted to a single allergen. The distribution of patients by allergens and gender for the specific sensitizations are shown in Table 1.

Out of 155 patients, 56 patients (36.1\%) had grade 1, 38 patients (24.5\%) had grade 2, 44 patients (28.4\%) had grade 3 and 17 patients (11\%) had grade 4 adenoid hypertrophy. A chi-square analysis demonstrated that adenoid hypertrophy did not differ among gender $\left(x^{2}: 7.7, p=0.052\right)$. There was a gender difference in allergen sensitivity in favor of males $\left(x^{2}: 8.6, p=0.003\right.$, OR: 0.3, Cl: 0.17-0.7).

An Anova analysis with post hoc Tukey test demonstrated that sneezing significantly indicated an allergic state. Although sensitivity to a single allergen or multiallergen did not have a significant difference $(p=0.98)$, there was a significant difference between the allergic and non-allergic group (non-allergic / single-allergen, $p=0.013$ and non-allergic / multiallergen, $p$ $=0.001$ ). Itching was found to be an important complaint and a physical finding in patients with multiallergen sensitivity, and there was a statistically significant difference between multiallergen sensitive patients and non-allergic patients $(p=0.001)$. An Anova analysis with post hoc Tukey test demonstrated that characteristics of nasal secretion was important examination finding in patients with multiallergen sensitivity, and there was a statistically significant difference between multiallergen sensi-

Table 2. Relationship between history /examination items and allergic sensitivity . (NS: not sensitive, SAS: single allergen sensitivity, MAS : multiple allergen sensitivity).

\begin{tabular}{|c|c|c|c|}
\hline $\begin{array}{l}\text { History / } \\
\text { examination item }\end{array}$ & $\begin{array}{l}\text { NS/SAS } \\
(p)\end{array}$ & $\begin{array}{l}\text { NS/MAS } \\
\qquad(p)\end{array}$ & $\begin{array}{l}\text { SAS/MAS } \\
\qquad(p)\end{array}$ \\
\hline Sneezing & 0.013 & 0.001 & 0.98 \\
\hline Nasal obstruction & 0.72 & 0.97 & 0.8 \\
\hline Rhinorrhea & 0.4 & 0.1 & 0.9 \\
\hline Itching & 0.17 & 0.004 & 0.82 \\
\hline Postnasal drip & 0.51 & 0.35 & 0.06 \\
\hline Coughing & 0.79 & 0.87 & 0.95 \\
\hline Snoring & 0.96 & 0.065 & 0.31 \\
\hline Turbinate color & 0.79 & 0.87 & 0.95 \\
\hline Turbinate hypertrophy & 0.98 & 0.83 & 0.95 \\
\hline $\begin{array}{l}\text { Characteristics of the nasal } \\
\text { secretions }\end{array}$ & 0.22 & 0.001 & 0.49 \\
\hline $\begin{array}{l}\text { Cobblestone appearance of } \\
\text { the posterior oropharyngeal } \\
\text { wall }\end{array}$ & 0.37 & 0.91 & 0.51 \\
\hline
\end{tabular}

Table 3. Symptoms according to the four point scale (FPS).

\begin{tabular}{lllll}
\multicolumn{1}{|c}{ Symptom } & \multicolumn{4}{c}{ FPS } \\
& $1(n, \%)$ & $2(n, \%)$ & $3(n, \%)$ & $4(n, \%)$ \\
\hline Sneezing & $24(15)$ & $62(40)$ & $40(25,8)$ & $29(18,7)$ \\
\hline Nasal obstruction & $33(21,3)$ & $49(31,6)$ & $42(27,1)$ & $31(20)$ \\
\hline Rhinoerrhea & $61(39,4)$ & $49(31,6)$ & $32(20,6)$ & $13(8,4)$ \\
\hline Itching & $54(34,8)$ & $50(32,3)$ & $36(23,2)$ & $15(9,7)$ \\
\hline Postnasal drip & $80(51,6)$ & $42(27,1)$ & $23(14,8)$ & $10(6,5)$ \\
\hline Cough & $64(41,3)$ & $50(32,3)$ & $31(20)$ & $10(6,5)$ \\
\hline Snoring & $86(55,5)$ & $37(23,9)$ & $18(11,6)$ & $14(9)$
\end{tabular}

The FPS is on a scale of 1 to $4: 1$, no complaints; 2 , mild complaints; 3 , moderate complaints; and 4, severe complaints.

tive patients and non-allergic patients $(p=0.001)$. Relationship between history /examination items and allergic sensitivity was demonstrated in Table 2.

Binary logistic regression analysis demonstrated that the history items of itching $(\mathrm{p}=0.008$, odds ratio $(\mathrm{OR})=1.7,95 \% \mathrm{Cl})$, and sneezing $(p=0.005, O R=1.95,95 \% \mathrm{Cl})$ were significant predictors for empirically diagnosing $A R$ in paediatric patients. Nasal obstruction $(p=0.83, O R=1,95 \% C l)$, rhinorrhea $(p=0.73, O R=$ $1,95 \% \mathrm{Cl})$, snoring $(\mathrm{p}=0.054, \mathrm{OR}=0.67,95 \% \mathrm{Cl})$, postnasal drip $(p=0.51, O R=0.8,95 \% \mathrm{Cl})$ and coughing $(p=0.28, O R=0.7$, $95 \% \mathrm{Cl}$ ) did not have statistical significance for diagnosing AR in paediatric patients empirically. The symptoms according to the sVAS are shown in Table 3.

Binary logistic regression analysis demonstrated that the following physical examination findings lacked significant predic-

Table 4. The relationship between adenoid hypertrophy and allergen sensitivity. In patients with smaller adenoids, allergen sensitivity was more prevalent.

Adenoid hypertrophy according to Parikh's classification

\begin{tabular}{lrrrr}
$\begin{array}{l}\text { Allergen } \\
\text { sensitivity }\end{array}$ & $1(\mathrm{~N}, \%)$ & $2(\mathrm{~N}, \%)$ & $3(\mathrm{~N}, \%)$ & $4(\mathrm{~N}, \%)$ \\
\hline None & $12(7,7 \%)$ & $16(10,3 \%)$ & $18(11,6 \%)$ & $8(5,2 \%)$ \\
\hline Single & $8(5,2 \%)$ & $5(3,2 \%)$ & $11(7,1 \%)$ & $1(0,6 \%)$ \\
\hline Multi & $36(23,2 \%)$ & $17(11 \%)$ & $15(9,7 \%)$ & $8(5,2 \%)$ \\
\hline p & 0,042 & & & \\
$\mathrm{X}^{2}$ & 13,05 & & & \\
\hline
\end{tabular}




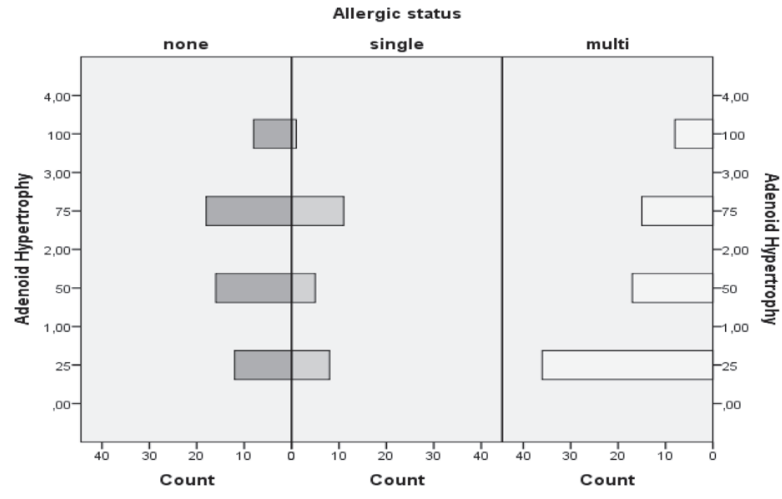

Figure 1. Relationship between adenoid hypertrophy and allergen sensitivity. In patients with smaller adenoids, allergen sensitivity was more prevalent.

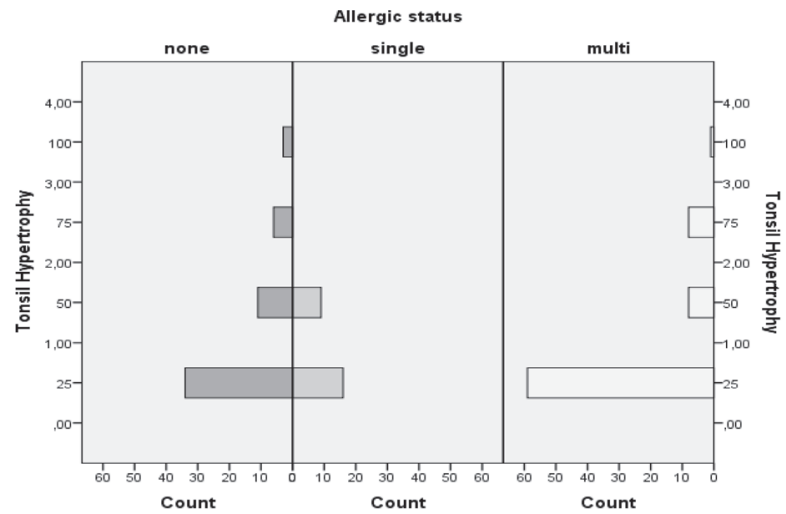

Figure 2. The relationship between allergic rhinitis and tonsil hypertrophy (there was no statistically significant relationship between tonsil hypertrophy and allergic status of the patient).

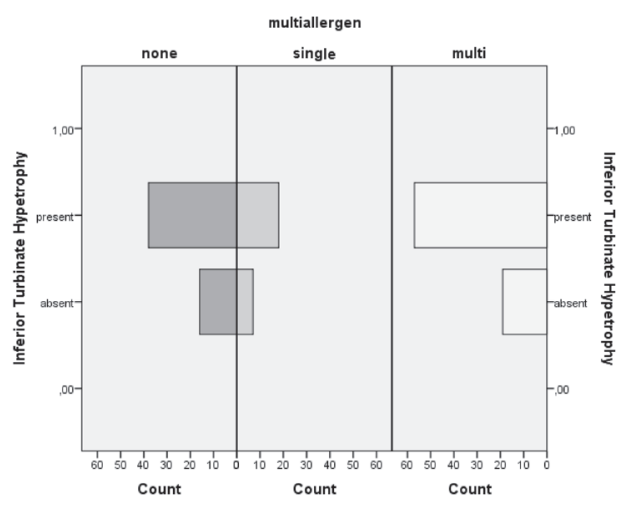

Figure 3. Relationship between allergic rhinitis and inferior turbinate hypertrophy (there was no statistically significant relationship between inferior turbinate hypertrophy and allergic status of the patient).

tive value for empirically diagnosing $A R$ in paediatric patients: turbinate color $(p=0.3, O R=0.6,95 \% \mathrm{Cl})$, turbinate hypertrophy $(p=0.3, O R=0.6,95 \% C l)$, tonsil hypertrophy $(p=0.2, O R=0.5$,
Table 5. The relationship between allergic rhinitis and tonsil hypertrophy and inferior turbinate hypertrophy.

\begin{tabular}{|ccc}
\hline & \multicolumn{2}{c}{ Allergic rhinitis } \\
\hline & Tonsil & Inferior turbinate \\
\hline P & 0,089 & 0,557 \\
\hline & $-0,137$ & 0,048 \\
\hline
\end{tabular}

r, Pearson correlation coefficient.

$95 \% \mathrm{Cl}$ ), and cobblestone appearance of the posterior oropharyngeal wall $(p=0.5, O R=0.8,95 \% \mathrm{Cl})$. The characteristics of the nasal secretion $(p<0.001, O R=6.4,95 \% \mathrm{Cl})$ and $\mathrm{AH}(\mathrm{p}=0.025$, $\mathrm{OR}=0.66,95 \% \mathrm{Cl}$ ) (correlation analysis demonstrated that there was a reverse relationship, and this result may be interpreted as smaller adenoid size might be a predictor of allergic rhinitis) did have significant predictive value in diagnosing AR in paediatric patients empirically.

A correlation analysis demonstrated that $\mathrm{AH}$ and allergen positivity had a significant negative correlation $(p=0.009, r=$ -0.208). Chi-square analysis identified a significant relationship between AH (four parameters according to Parikh's classification) and AS (Table 4, Figure 1). A correlation analysis found no significant relationship between allergen hypersensitivity and tonsil hypertrophy or inferior turbinate hypertrophy (Table 5, Figures 2, 3).

\section{Discussion}

Several studies have investigated the possible relationship between $\mathrm{AH}$ and allergy, but there is no consensus whether AR is a possible cause of $\mathrm{AH}$.

In 2007, Modrzyski et al. ${ }^{(13)}$ reported that the presence of AR increases the likelihood of $\mathrm{AH}$ occurring. Their study group consisted of 436 children between 4 and 9 years old with AR, bronchial asthma, or atopic dermatitis hypersensitive to house dust mites, with 229 non-atopic children (negative interview and prick test) of similar age used as controls. They used a flexible fiberoptic nasopharyngoscope to examine the nasopharynx. They concluded that AH occurred significantly more frequently in children with AR related to hypersensitivity to dust mites, than in children with other allergic diseases (asthma/atopic dermatitis) or with no allergies. Sadeghi-Shabesteri et al. ${ }^{(3)}$ reported similar results and found a meaningful correlation between the positive skin prick test and high serum IgE level in patients with adenotonsillar hypertrophy compared with other children. The main drawback of their study was that it used lateral neck X-rays to assess $\mathrm{AH}$.

Countering these studies, Karaca et al. ${ }^{(4)}$ reported a non-sig- 
nificant relationship between $\mathrm{AH}$ and the results of skin prick tests. Lateral neck X-rays were used to assess AH. They found a significant relationship between tonsil size and skin prick test results and concluded that allergen sensitivity plays a role in childhood tonsillar hypertrophy. A recent study demonstrated that increased anterior nasal obstruction leads to smaller adenoids as assessed using nasal endoscopy; large adenoids were related to the absence of allergy and large turbinates to smaller adenoids ${ }^{(14)}$.

We found a significant inverse relationship between adenoid size and the presence of allergy (chi-square: $p=0.042, x^{2}=13$ (5), Pearson correlation analysis: $p=0.009, r=-0.208$ ). As the adenoid size grows, the chance of AR decreases. Our findings confirm the report by Ameli et al. ${ }^{(14)}$ that the presence of allergy is associated with smaller adenoid size. No significant correlation was demonstrated between AR and turbinate hypertrophy or tonsil hypertrophy. The value of nasal endoscopy signs for predicting AR was evaluated using logistic regression. Contrary to the findings of Ameli et al. ${ }^{(8)}$, turbinate hypertrophy was not found to be a predictor of $A R$, while the characteristics of the nasal secretions did predict AR $(p<0.001, O R=6.3)$. This difference was significant in patients with multiallergen sensitivity $(p=0.001)$. In addition, the predictive value of the history was investigated. A logistic regression analysis demonstrated that the history items itching $(p=0.008$, odds ratio $(O R)=1.7$ and sneezing ( $p=0.005, O R=1.95$ ) had significant predictive value for empirically diagnosing AR in paediatric patients. Regardless of allergic sensitivity, sneezing was a distinguishing symptom of allergic patients. But, itching seemed to be a more significant symptom in patients with multiallergen sensitivity. Rhinitis is characterized by at least two of either rhinorrhea, blockage, sneezing, or itching ${ }^{(15,16)}$. Our results concur with this report. To our knowledge, our study is the first to evaluate the value of history in the empirical diagnosis of AR.

It is a well-known that boys are more sensitive to allergens ${ }^{(17,18)}$. Consistent with the literature, we found a statistically significant gender difference. On the contrary, in a recent study conducted in a primary care clinic, the authors did not report any gender differences ${ }^{(19)}$. The discrepancy may have arisen as the studies conducted in referral hospitals may have selected different pools of patients.

The main limitation of this study is that nasal endoscopy signs like turbinate color and turbinate hypertrophy have great inter-rater variability, while the characteristics of nasal secretion, which were found to predict $A R$, have significant inter-rater agreement ${ }^{(9)}$. AH is most prevalent at 4-7 years of age, while the prevalence of $A R$ increases with age ${ }^{(15)}$. A narrow age group in a smaller study might have yielded different results.

\section{Conclusion}

In primary and secondary care, AR is usually treated empirically. The characteristics of nasal secretions, itching, sneezing, and coughing were found to predict AR in children. Clues that aid a precise diagnosis might prevent treatment failure. $\mathrm{AH}$ was found to be inversely related to AR in this study. This is a controversial topic and studies enrolling narrow age groups are needed.

\section{Acknowledgement}

This article was presented at the 10th Turkish National Rhinology Congress 2014 in Antalya, Turkey.

\section{Author contributions}

EE: Substantial contributions to the conception, design of the work; and the acquisition, analysis, interpretation of data for the work, drafting the work, revising the paper critically for important intellectual content; SA: Substantial contributions to the conception, design of the work; SBE: Substantial contributions to the the acquisition, analysis, interpretation of data for the work; TN: Substantial contributions to the the acquisition, analysis, interpretation of data for the work; CŞK: Substantial contributions to the the acquisition, analysis, interpretation of data for the work; DC: Substantial contributions to the conception, design of the work; KÖ: Substantial contributions to the conception, design of the work; All authors gave final approval of the version to be published.

\section{Conflict of interest}

None to report.

\section{References}

1. Van Den Akker EH, Hoes AW, Burton MJ Schilder AG. Large international differences in (adeno)tonsillectomy rates. Clin Otolaryngol Allied Sci. 2004; 29: 161-164.

2. Wright AL, Holberg CJ, Martinez FD, Halonen M, Morgan W, Taussig LM Epidemiology of physician-diagnosed allergic rhinitis in childhood. Pediatrics. 1994; 94: 895-901.

3. Sadeghi-Shabestari M, Jabbari Moghaddam $Y$, Ghaharri H. Is there any correla- tion between allergy and adenotonsillar tissue hypertrophy? Int J Pediatr Otorhinolaryngol. 2011; 75: 589-891.

4. Karaca CT, Toros SZ, Noşeri H, et al. Role of allergy in children with adenotonsillar hypertrophy. J Craniofac Surg. 2012 ;23: e611-613.

5. Kindermann CA, Roithmann R, Lubianca Neto JF. Sensitivity and specificity of nasal flexible fiberoptic endoscopy in the diagnosis of adenoid hypertrophy in children. Int J Pediatr Otorhinolaryngol. 2008; 72: 63-67.
6. Lertsburapa K, Schroeder JW Jr, Sullivan C. Assessment of adenoid size: A comparison of lateral radiographic measurements, radiologist assessment, and nasal endoscopy. Int J Pediatr Otorhinolaryngol. 2010; 74: 1281-1285.

7. Mlynarek A, Tewfik MA, Hagr A, et al. Lateral neck radiography versus direct video rhinoscopy in assessing adenoid size. J Otolaryngol. 2004; 33: 360-365.

8. Ameli F, Brocchetti F, Tosca MA, Signori A, Ciprandi G. Nasal endoscopy in chil- 
dren with suspected allergic rhinitis. Laryngoscope. 2011; 121: 2055-2059.

9. Eren E, Aktaş A, Arslanoğlu S, Kopar A, et al. Diagnosis of allergic rhinitis: inter-rater reliability and predictive value of nasal endoscopic examination: a prospective observational study. Clin. Otolaryngol. 2013; 38: 481-486.

10. Ciprandi G, Tosca MA, Signori A, Ameli F. Comparison between symptoms and endoscopy in children with nasal obstruction. Int J Pediatr Otorhinolaryngol. 2010 74: 1405-1408.

11. Brodsky L Modern assessment of tonsils and adenoids. Pediatr Clin North Am 1989; 36: 1551-1569.

12. Parikh SR, Coronel M, Lee JJ, Brown SM. Validation of a new grading system for endoscopic examination of adenoid hypertrophy. Otolaryngol Head Neck Surg. 2006; 135: 684-687.

13. Modrzynski M, Zawisza E. An analysis of the incidence of adenoid hypertrpohy in aller- gic children. Int J Pediatr Otorhinolaryngol. 2007; 71: 713-719.

14. Ameli F, Brocchetti F, Tosca MA, Signori A Ciprandi G. Adenoidal hypertrophy and allergic rhinitis: is there an inverse relationship? Am J Rhinol Allergy. 2013; 27: 5-10

15. Roberts $G$, Xatzipsalti M, Borrego LM,et al. Paediatric rhinitis: position paper of the European Academy of Allergy and Clinical Immunology. Allergy. 2013; 68: 1102-1116.

16. Hellings PW, Scadding G, Alobid I, et al Executive summary of European Task Force document on diagnostic tools in rhinology. Rhinology. 2012; 50: 339-352.

17. De Jong $A B$, Dikkeschei LD, Brand PL. Sensitization patterns to food and inhalant allergens in childhood: a comparison of non-sensitized, monosensitized, and polysensitized children. Pediatr Allergy Immunol. 2011; 22: 166-171.

18. Wallace DV, Dykewicz MS, Bernstein DI, et al. The diagnosis and management of rhinitis: an updated practice parameter. J Allergy
Clin Immunol. 2008; 122 (2 Suppl): S1-84

19. De Bot CM, Röder E, Pols DH, et al. Sensitisation patterns and association with age, gender, and clinical symptoms in children with allergic rhinitis in primary care: a cross-sectional study. Prim Care Respir J. 2013; 22: 155-160

Erdem Eren, MD

Piri Reis Mh.

İnönü Cd. No : 252/17

Konak/İzmir

Turkey

E-mail: erd2eren@yahoo.com 